\title{
Elucidating the Electrochemical Activity of Electrolyte-Insoluble Polysulfide Species in Lithium-Sulfur Batteries
}

\author{
Michael J. Klein, ${ }^{\text {a,* }}$ Karel Goossens, ${ }^{\text {b,c }}$ Christopher W. Bielawski, ${ }^{c, d}$ \\ and Arumugam Manthiram ${ }^{\mathrm{a}, * *, \mathrm{z}}$
}

\author{
${ }^{a}$ Materials Science and Engineering Program and Texas Materials Institute, The University of Texas at Austin, Austin, \\ Texas 78712, USA \\ ${ }^{b}$ Department of Chemistry, The University of Texas at Austin, Austin, Texas 78712, USA \\ ${ }^{c}$ Center for Multidimensional Carbon Materials, Institute for Basic Science, Ulsan 44919, Korea \\ ${ }^{d}$ Department of Chemistry and Department of Energy Engineering, Ulsan National Institute of Science and \\ Technology, Ulsan 44919, Korea
}

\begin{abstract}
The direct synthesis of $\mathrm{Li}_{2} \mathrm{~S}_{2}$, a proposed solid intermediate in the discharge of lithium-sulfur ( $\mathrm{Li}-\mathrm{S}$ ) batteries, was accomplished by treating elemental lithium with sulfur in liquid ammonia at $-41^{\circ} \mathrm{C}$. The as-synthesized product was analyzed by X-ray photoelectron spectroscopy (XPS) as well as X-ray diffraction (XRD) and determined to be a mixture of crystalline $\mathrm{Li}_{2} \mathrm{~S}$, amorphous $\mathrm{Li}_{2} \mathrm{~S}_{2}$, and higher-order polysulfides $\left(\mathrm{Li}_{2} \mathrm{~S}_{\mathrm{x}}, \mathrm{x}>2\right)$. Monitored filtration followed by a tailored electrochemical approach was used to successfully remove the higher-order polysulfides and yielded a powder, which was determined by XPS to be comprised of $\sim 9 \mathrm{~mol} \%$ insoluble polysulfide species (mainly $\mathrm{Li}_{2} \mathrm{~S}_{2}$ ) and $\sim 91 \mathrm{~mol} \% \mathrm{Li}_{2} \mathrm{~S}$. This material was discharged galvanostatically in an electrochemical cell and, despite the lack of soluble polysulfide species, was shown to exhibit a discharge plateau at $\sim 2.1 \mathrm{~V}$ vs. $\mathrm{Li} / \mathrm{Li}^{+}$. This result confirmed the electrochemical reducibility of electrolyte-insoluble polysulfides in Li-S batteries. Moreover, it was determined that the reduction of solid polysulfides was confined to areas where the sulfur-sulfur bonds were in intimate contact with the conductive current collector. Finally, it was observed that commercially available $\mathrm{Li}_{2} \mathrm{~S}$ samples contain significant quantities of polysulfide-type impurities.

(C) The Author(s) 2016. Published by ECS. This is an open access article distributed under the terms of the Creative Commons Attribution Non-Commercial No Derivatives 4.0 License (CC BY-NC-ND, http://creativecommons.org/licenses/by-nc-nd/4.0/), which permits non-commercial reuse, distribution, and reproduction in any medium, provided the original work is not changed in any way and is properly cited. For permission for commercial reuse, please email: oa@electrochem.org. [DOI: 10.1149/2.0051610jes] All rights reserved.
\end{abstract}

Manuscript submitted April 11, 2016; revised manuscript received June 13, 2016. Published July 29, 2016.

Lithium-sulfur ( $\mathrm{Li}-\mathrm{S})$ batteries have emerged in recent years as promising next-generation energy storage devices to meet the growing need for affordable, highly energy-dense systems for electrical vehicles and grid-scale applications. ${ }^{1,2}$ The high theoretical gravimetric energy density $\left(1672 \mathrm{mAh} \mathrm{g}^{-1}\right)$ of the Li-S system coupled with the low-cost and abundance of sulfur offers significant advantages over current lithium-ion batteries. ${ }^{2}$ However, the conversion nature of the Li-S system leads to a complicated charge/discharge mechanism that passes through multiple soluble and insoluble species on each halfcycle. $^{2,3}$ This opens up a multitude of mechanisms for active material loss during long-term cycling. Additionally, the insulating nature of sulfur and lithium sulfide, the final discharge product, limits the rate capability of the system and necessitates forming composite cathodes with a conductive material such as carbon. ${ }^{1,2}$

Of particular concern to the loss of capacity with cycling is the deposition of electrochemically-inaccessible solid sulfide species $\left(\mathrm{Li}_{2} \mathrm{~S}_{\mathrm{x}}\right.$, $\mathrm{x}<3){ }^{4,5}$ Multiple literature reports have reached different conclusions on the existence of the solid, electrolyte-insoluble species $\mathrm{Li}_{2} \mathrm{~S}_{2}$ and whether it forms as a solid intermediate during the discharge of Li-S batteries. ${ }^{5-12}$ Recent studies have suggested there may be separate reaction pathways that are followed at different points during $\mathrm{Li}-\mathrm{S}$ discharge: one where only $\mathrm{Li}_{2} \mathrm{~S}$ is formed during reduction of soluble polysulfides $\left(\mathrm{Li}_{2} \mathrm{~S}_{\mathrm{x}}, \mathrm{x}>2\right)$, and a second where both $\mathrm{Li}_{2} \mathrm{~S}$ and $\mathrm{Li}_{2} \mathrm{~S}_{2}$ are formed simultaneously. ${ }^{11}$ The question of whether any $\mathrm{Li}_{2} \mathrm{~S}_{2}$ that forms can then be reduced is debated in the literature. ${ }^{8}$ The existence and reducibility of $\mathrm{Li}_{2} \mathrm{~S}_{2}$ is particularly important, as the formation of any $\mathrm{Li}_{2} \mathrm{~S}_{2}$ during discharge that cannot be reduced to $\mathrm{Li}_{2} \mathrm{~S}$ significantly limits the theoretical capacity of the Li-S system and would cause continued capacity loss with extended cycling. It is also important to the fundamental understanding of the Li-S battery discharge mechanism whether or not $\mathrm{Li}_{2} \mathrm{~S}_{2}$ is the first solid species formed, as the formation of solid sulfides is involved in reactions that account for $75 \%$ of the theoretical Li-S capacity. ${ }^{9,11}$

\footnotetext{
*Electrochemical Society Student Member.

**Electrochemical Society Fellow.

${ }^{\text {zE} E-m a i l: ~ r m a n t h @ m a i l . u t e x a s . e d u ~}$
}

The literature presents several chemical syntheses of $\mathrm{Li}_{2} \mathrm{~S}_{2}$, notably by the stoichiometric reaction of sulfur and either lithium or $\mathrm{Li}_{2} \mathrm{~S}$ in liquid ammonia at low temperature ${ }^{13,14}$ or by the reduction of sulfur with lithium triethylborohydride $\left(\mathrm{Li}\left(\mathrm{C}_{2} \mathrm{H}_{5}\right)_{3} \mathrm{BH}\right)$ in organic solvents. ${ }^{15}$ However, the work first reporting that $\mathrm{Li}_{2} \mathrm{~S}_{2}$ was formed via $\mathrm{Li}\left(\mathrm{C}_{2} \mathrm{H}_{5}\right)_{3} \mathrm{BH}$ reduction was not supported by the characterized data; rather, the product was used as an intermediate to organosulfur compounds. ${ }^{15}$ Moreover, a recent study duplicated the synthetic approach and reported the product to be a stoichiometric mixture of $\mathrm{Li}_{2} \mathrm{~S}$ and amorphous $\mathrm{Li}_{2} \mathrm{~S}_{6}{ }^{6}$

While $\mathrm{Li}_{2} \mathrm{~S}_{2}$ does not appear in the phase diagram of the lithium-sulfur system at room temperature, it may form as a stable phase at low temperatures or as a metastable phase via electrochemical processes at room temperature., ${ }^{6,16}$ Theoretical studies have indicated that $\mathrm{Li}_{2} \mathrm{~S}_{2}$ could be either slightly stable ${ }^{10,17}$ or slightly unstable ${ }^{18}$ to decomposition to $\mathrm{Li}_{2} \mathrm{~S}$ and sulfur at room temperature.

For a sample prepared via the low-temperature reaction in ammonia, ultraviolet-visible spectroscopy (UV-vis) on the saturated ammonia solution at room temperature showed a signal at $285 \mathrm{~nm}$, which was tentatively assigned to $\mathrm{Li}_{2} \mathrm{~S}_{2} \cdot{ }^{13}$ This signal is close to a signal at $\sim 270 \mathrm{~nm}$ reported for electrochemically-generated $\mathrm{Li}_{2} \mathrm{~S}_{2}$ in tetraethylene glycol dimethyl ether (TEGDME). ${ }^{9}$ Additional evidence for the formation of $\mathrm{Li}_{2} \mathrm{~S}_{2}$ was obtained via thermogravimetric analysis (TGA), which showed that the product started to decompose to $\mathrm{Li}_{2} \mathrm{~S}$ above $50^{\circ} \mathrm{C},{ }^{14}$ although these data may be obfuscated by the presence of amorphous $\mathrm{Li}_{2} \mathrm{~S}_{6}{ }^{6}$ There does not appear to be any report that unambiguously identifies $\mathrm{Li}_{2} \mathrm{~S}_{2}$ in the solid state.

In this work, we report that a mixture of sulfide species, including $\mathrm{Li}_{2} \mathrm{~S}_{2}$, forms upon treatment of elemental lithium with sulfur in liquid ammonia. We discuss filtration schemes that effectively remove soluble higher-order polysulfides and yield a mixture of predominantly $\mathrm{Li}_{2} \mathrm{~S}_{2}$ and $\mathrm{Li}_{2} \mathrm{~S}$. Finally, we examine the electrochemical activity of insoluble lithium polysulfides by demonstrating the reducibility of the $\mathrm{Li}_{2} \mathrm{~S}_{2}$ fraction in the synthesized sample as well as in commercial samples of $\mathrm{Li}_{2} \mathrm{~S}$ in which polysulfide-type impurities were identified. 


\section{Experimental}

$\boldsymbol{L i}_{2} \mathrm{~S}_{2}$ synthesis.-The procedure was adapted from several literature reports. ${ }^{13,14,19-24}$ Before starting the synthesis, glassware was thoroughly cleaned to minimize the decomposition of the lithiumammonia solution prepared during synthesis. ${ }^{25-27}$ The glassware was soaked for $60 \mathrm{~min}$ in a freshly prepared NoChromix solution $(45 \mathrm{~g}$ of NoChromix, i.e. mainly $\left(\mathrm{NH}_{4}\right)_{2} \mathrm{~S}_{2} \mathrm{O}_{8}$, was dissolved in $2 \mathrm{~L}$ of concentrated sulfuric acid), after which it was rinsed with Milli-Q water. It was then soaked for $30 \mathrm{~min}$ in $30 \% \mathrm{NH}_{4} \mathrm{~F}$ in Milli-Q water, rinsed again with Milli-Q water and baked and dried for $60 \mathrm{~min}$ at $120^{\circ} \mathrm{C}$ in a vacuum oven. After this treatment, the glassware was soaked for 20 min in $1 \mathrm{~N} \mathrm{HNO}_{3}$, rinsed with Milli-Q water, and dried for $48 \mathrm{~h}$ at $120^{\circ} \mathrm{C}$ under dynamic vacuum and then for $24 \mathrm{~h}$ in a gravity oven at $200^{\circ} \mathrm{C}$.

An argon-filled $50 \mathrm{~mL}$ Schlenk flask (Kjeldahl flask) charged with a glass-coated Teflon stir bar and sealed with a glass stopper, all of which were treated according to the cleaning procedure described above, was inserted into a high-purity argon-filled glove box $\left(\mathrm{O}_{2}<1 \mathrm{ppm}, \mathrm{H}_{2} \mathrm{O}<1 \mathrm{ppm}\right)$. Inside the glove box, a stoichiometric 1 : 1 ratio of sulfur powder (Acros, 99.999\%, sublimed and then kept overnight under dynamic vacuum $(2.0 \mathrm{~Pa})$ at room temperature; $817.8 \mathrm{mg}, 3.188 \mathrm{mmol} \mathrm{S}_{8}$ ) and small, freshly cut lithium metal pieces (Aldrich, 99.9\% trace metals basis; $177.0 \mathrm{mg}, 25.504 \mathrm{mmol} \mathrm{Li}$ ) were weighed and added to the Schlenk flask, which was then sealed again with a greased glass stopper. The flask was transferred to a Schlenk line and kept overnight under dynamic vacuum (2.0 Pa) at room temperature. The Schlenk line was flushed with anhydrous high-purity argon gas (Praxair, AR 5.0UH: $\mathrm{O}_{2}<1$ ppm, $\mathrm{H}_{2} \mathrm{O}<3$ ppm, $\mathrm{N}_{2}<$ $4 \mathrm{ppm})$. The next day the Schlenk flask was backfilled with argon and placed in a bath of dry ice in acetone at ca. $-78^{\circ} \mathrm{C}$. By means of chemical-resistant Tygon 2375 tubing and appropriate fittings, anhydrous ammonia gas (Praxair, AM 5.0RS: $\mathrm{O}_{2}<0.5$ ppm, $\mathrm{H}_{2} \mathrm{O}<$ $1 \mathrm{ppm}, \mathrm{N}_{2}<1.5 \mathrm{ppm}$ ) was allowed to flow, via a drying tube filled with sodium metal, through the Schlenk flask until about $45 \mathrm{~mL}$ of liquid ammonia had condensed. The typical blue color resulting from the dissolution of lithium in liquid ammonia could be quickly observed. The cooling bath was changed to dry ice in a mixture of ethanol and ethylene glycol $(40 / 60 \mathrm{v} / \mathrm{v})$ to raise the temperature to ca. $-41^{\circ} \mathrm{C} .^{28}$ The reaction mixture was magnetically stirred (at $650 \mathrm{rpm}$ ) for $5 \mathrm{~h}$ under continuous cooling. During this time, the reaction mixture developed an orange-yellow color. When stirring was paused, a yellow precipitate and an orange supernatant could be observed. After $5 \mathrm{~h}$, the cooling bath was changed to dry ice in a mixture of ethanol and ethylene glycol $(20 / 80 \mathrm{v} / \mathrm{v})$ to raise the temperature to ca. $-28^{\circ} \mathrm{C}{ }^{28}$ Under continued stirring and a flux of argon, the ammonia was expelled into a trap cooled with liquid nitrogen, and was finally completely replaced by argon. The Schlenk flask was then removed from the cooling bath and placed under dynamic vacuum overnight. The next day the flask was connected, under a flow of argon, to a Schlenk filtration setup that was filled with argon and was equipped with an addition funnel filled with $40 \mathrm{~mL}$ of anhydrous, degassed THF (Note: the THF was dried over sodium-benzophenone, collected in an oven-dried Schlenk flask, subjected to five freeze-pump-thaw cycles and transferred to the addition funnel via cannula transfer). The THF was added to the yellow solid residue in the reaction flask, and the resulting suspension was magnetically stirred for $30 \mathrm{~min}$ at room temperature. Stirring was then ceased and the Schlenk filtration setup was rotated to separate the clear, dark-yellow to brown filtrate from the yellow powder by means of a filtration tube with frit. Finally, the Schlenk flask and the Schlenk filtration tube were decoupled from the rest of the setup under a flow of argon, and sealed. The solid residue was further dried for $16 \mathrm{~h}$ under dynamic vacuum at room temperature, after which the Schlenk flask was backfilled with argon and transferred into the high-purity argon-filled glove box for all further material processing.

Filtration/polysulfide extraction in DME/DOL.-The solid synthesis product $\left(\mathrm{Li}_{2} \mathrm{~S}_{\mathrm{x}}\right)$ was washed with $\sim 20 \mathrm{~mL}$ of a mixture of 1,2-dimethoxyethane (DME, Sigma-Aldrich, 99.5\%) and 1,3-dioxolane (DOL, Acros Organics, 99.5+\%, stabilized) (50/50 v/v, "DME/DOL"). The solution was filtered through $450 \mathrm{~nm}$ and $200 \mathrm{~nm}$ pore size PTFE filters (Millipore Fluoropore) and $100 \mathrm{~nm}$ pore size nylon filters (Sterlitech Corporation) on a vacuum line in the glove box. The solid powder was isolated from the filter and the liquid filtrate was collected for analysis. For initial "filter-free" polysulfide extractions, the $\mathrm{Li}_{2} \mathrm{~S}_{\mathrm{x}}$ powders were mixed with $20 \mathrm{~mL}$ DME/DOL and magnetically stirred for several hours. The solutions were allowed to settle overnight and the liquid supernatant was removed via micropipette and collected. For the final extractions, in place of magnetic stirring, the mixture of $\mathrm{Li}_{2} \mathrm{~S}_{\mathrm{x}}$ in DME/DOL was agitated by hand to minimize any mechanical grinding action.

Carbon nanofiber (CNF) paper synthesis.-CNF paper current collectors were fabricated as reported in the literature. ${ }^{29}$ Briefly, $180 \mathrm{mg}$ CNFs (Aldrich, pyrolytically stripped, > 98\%) were added to $650 \mathrm{~mL}$ deionized water and $50 \mathrm{~mL}$ isopropanol (IPA, Fisher, 99.9\%) and ultrasonicated. The solution was vacuum filtered and dried overnight under vacuum at $50^{\circ} \mathrm{C}$. The $\mathrm{CNF}$ paper was separated from the filter and punched into circular current collectors.

Electrochemical cell fabrication and characterization.-CR2032 coin cells were fabricated to enable electrochemical characterization. Electrolyte solution was prepared by dissolving $1 \mathrm{M}$ lithium bis(trifluoromethanesulfonyl)imide (LiTFSI, SynQuest Laboratories, 99.5\%) in DME/DOL. For catholyte-type cells, 1 M LiTFSI was added to the solution being analyzed to form a liquid catholyte. For solid slurry-type cells, solid $\mathrm{Li}_{2} \mathrm{~S}_{\mathrm{x}}$ powder was added to the electrolyte solution and magnetically stirred to form a solid slurry. To fabricate the cells, $30 \mu \mathrm{L}$ of the catholyte or solid slurry was deposited by micropipette on a CNF current collector. For control cells, $30 \mu \mathrm{L}$ of electrolyte was used in place of the catholyte or solid slurry. The cathode was covered by a polypropylene/polyethylene (Celgard 2325) separator and $20 \mu \mathrm{L}$ electrolyte was added to the anode side. The coin cells were sealed after addition of a $1 \mathrm{~cm}^{2}$ lithium metal anode. Cells were discharged galvanostatically on an Arbin multichannel cycler to $1.8 \mathrm{~V}$ (vs. $\mathrm{Li} / \mathrm{Li}^{+}$).

Ultraviolet-visible spectroscopy (UV-vis)._-DME/DOL was used as a blank solution. Sample solutions were prepared by collecting $5 \mathrm{~mL}$ of filtrate after vacuum filtration of the $\mathrm{Li}_{2} \mathrm{~S}_{\mathrm{x}}$ powder. Inside the glove box, $3 \mathrm{~mL}$ of filtrate were added to $1-\mathrm{cm}$ path-length quartz cuvettes with PTFE-lined caps to prevent air exposure. UV-vis absorption spectra were collected from $250 \mathrm{~nm}$ to $800 \mathrm{~nm}$. The remaining sample solutions were then sequentially analyzed and diluted with blank solution until the absorption spectrum did not saturate the detector in the ultraviolet region. " $\mathrm{Li}_{2} \mathrm{~S}_{6}$ " reference solution was prepared by mixing $5: 1$ stoichiometric amounts of sulfur powder : $\mathrm{Li}_{2} \mathrm{~S}$ powder in blank solution followed by magnetically stirring overnight at $60^{\circ} \mathrm{C}$. The reference solution was also sequentially diluted until the detector did not saturate.

$\boldsymbol{X}$-ray diffraction $(\boldsymbol{X} \boldsymbol{R D}) .-\mathrm{Li}_{2} \mathrm{~S}_{\mathrm{x}}$ powder was prepared for XRD by being sealed between polyimide tape and a $0.1 \mathrm{~mm}$ thick polyimide film to protect the sample from oxidation. Powder diffraction data were collected through the polyimide thin film using filtered $\mathrm{Cu} \mathrm{K} \alpha$ radiation $(\lambda=1.5148 \AA)$, from $2 \theta=25^{\circ}$ to $2 \theta=75^{\circ}$.

X-ray photoelectron spectroscopy (XPS).- - Samples of synthesized $\mathrm{Li}_{2} \mathrm{~S}_{\mathrm{x}}$ and commercial reference $\mathrm{Li}_{2} \mathrm{~S}$ from two sources $(99.9 \%$ trace metals basis from Alfa Aesar and $99.98 \%$ trace metals basis from Aldrich) were embedded in indium foil (Sigma-Aldrich, 99.999\%) in a glove box and transferred immediately within an in-house designed capsule that interfaces directly with the ultra-high vacuum XPS instrument, allowing sample transport and pump-down with no exposure to the atmosphere. Surface characterization was performed with monochromated $\mathrm{Al} \mathrm{K} \alpha$ radiation $(\mathrm{h} \nu=1486.5 \mathrm{eV})$ at $150 \mathrm{~W}(10$ $\mathrm{mA}$ and $15 \mathrm{kV}$ ). A concentric hemispherical analyzer was used to measure electron energies. A charge neutralizer was employed with 
the insulating powders and the spectra were corrected with a linear offset such that the adventitious (graphite-like) carbon peak in the carbon $1 \mathrm{~s}$ spectrum was set to $284.6 \mathrm{eV} .^{30}$ Individual region spectra were collected using a $20 \mathrm{eV}$ pass energy and $0.1 \mathrm{eV}$ step sizes with $800 \mathrm{~ms}$ dwell times. $\mathrm{Ar}^{+}$ions were used to sputter the samples to identify any bulk vs. surface effects in the powders.

XPS spectra were analyzed with CasaXPS software (Casa Software Ltd.). Spectra were fit with a Shirley-type background. Spectrum deconvolution was performed with individual peak line-shapes with $70 \%$ Gaussian and $30 \%$ Lorentzian character. S $2 p$ signals were fit with $\mathrm{S} 2 \mathrm{p}_{1 / 2}$ peaks offset by $1.18 \mathrm{eV}^{31}$ from the corresponding $2 \mathrm{p}_{3 / 2}$ peaks and with equal full-width at half-maximum (FWHM) and half the integrated area of the $2 p_{3 / 2}$ peaks. For ease of discussion, all $S 2 p$ signals will be referred to by the center of their larger $2 \mathrm{p}_{3 / 2}$ peak. Li/S stoichiometry was calculated using the standard relative sensitivity factors (RSFs) provided by CasaXPS for the Kratos XPS instrument used.

\section{Results and Discussion}

The air-sensitive powder obtained after the initial filtration from THF had a rich yellow color. As shown in Figure 1, the XRD pattern exhibited several features, notably all the observable peaks could be indexed to the antifluorite phase of $\mathrm{Li}_{2} \mathrm{~S}$ (JCPDS No. 23-0369). The peaks indexed to $\mathrm{Li}_{2} \mathrm{~S}$ were significantly broadened, consistent with the presence of sub-micron sized $\mathrm{Li}_{2} \mathrm{~S}$ particles. The broad background at $2 \theta<40^{\circ}$ was attributed to the polyimide film used to protect the sample from oxidation. The pattern lacked any peaks associated with crystalline sulfur, consistent with all of the original sulfur used in the synthesis being consumed. The lack of a sulfur signal, combined with the yellow color of the powder (in contrast to the white or off-white color of $\mathrm{Li}_{2} \mathrm{~S}$ powder) suggested to us a solid polysulfide species might be present. The sodium polysulfide analogs, such as $\mathrm{Na}_{2} \mathrm{~S}_{2}$ and $\mathrm{Na}_{2} \mathrm{~S}_{4}$, are known to be yellow. ${ }^{14}$ However, the lack of any additional peaks matching simulated XRD patterns of theoretical $\mathrm{Li}_{2} \mathrm{~S}_{2}$ structures ${ }^{17}$ suggested to us that any polysulfide species present were amorphous. Additionally, it did not rule out the product being only a mixture of $\mathrm{Li}_{2} \mathrm{~S}$ and $\mathrm{Li}_{2} \mathrm{~S}_{6}$ as reported for the product obtained from the abovementioned synthetic procedure that utilized $\mathrm{Li}\left(\mathrm{C}_{2} \mathrm{H}_{5}\right)_{3} \mathrm{BH} .{ }^{6}$

XPS spectra taken of the "as-synthesized" $\mathrm{Li}_{2} \mathrm{~S}_{\mathrm{x}}$ (i.e., only filtered from THF on the Schlenk line) is presented in Figure 2, after background subtraction. The $\mathrm{S} 2 \mathrm{p}$ region spectrum was deconvolved and fit with three peaks, each with clear physical interpretations for the corresponding sulfur environment. The peak at the lowest binding energy, $159.8 \mathrm{eV}$, was assigned to " $\mathrm{Li}_{2} \mathrm{~S}$-type" sulfur atoms, ${ }^{32}$ i.e., sulfur atoms bonded to two lithium atoms and consistent with the anionic $\mathrm{S}^{2-}$ species. $^{33,34}$

The peak at slightly higher binding energy, $161.5 \mathrm{eV}$, was ascribed to "terminal" sulfur, i.e., a sulfur atom that is bonded to one lithium

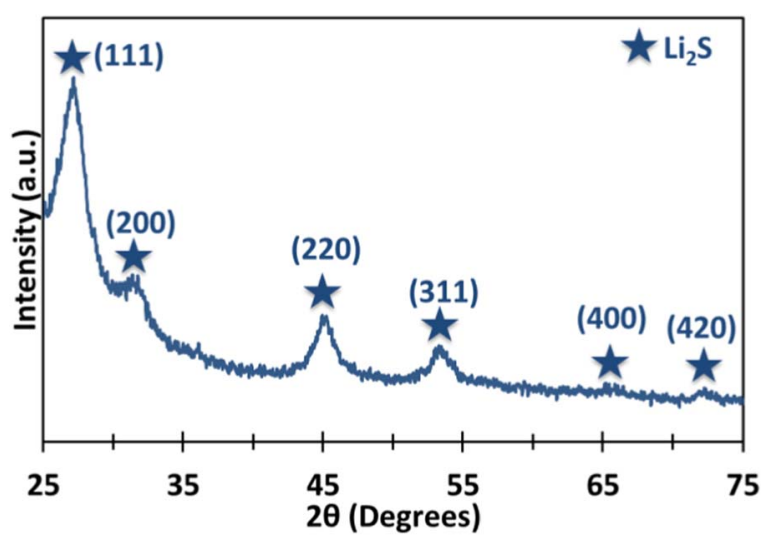

Figure 1. XRD pattern of the synthesized $\mathrm{Li}_{2} \mathrm{~S}_{\mathrm{X}}$ after initial filtration from THF. Crystalline $\mathrm{Li}_{2} \mathrm{~S}$ peaks are identified and indexed.

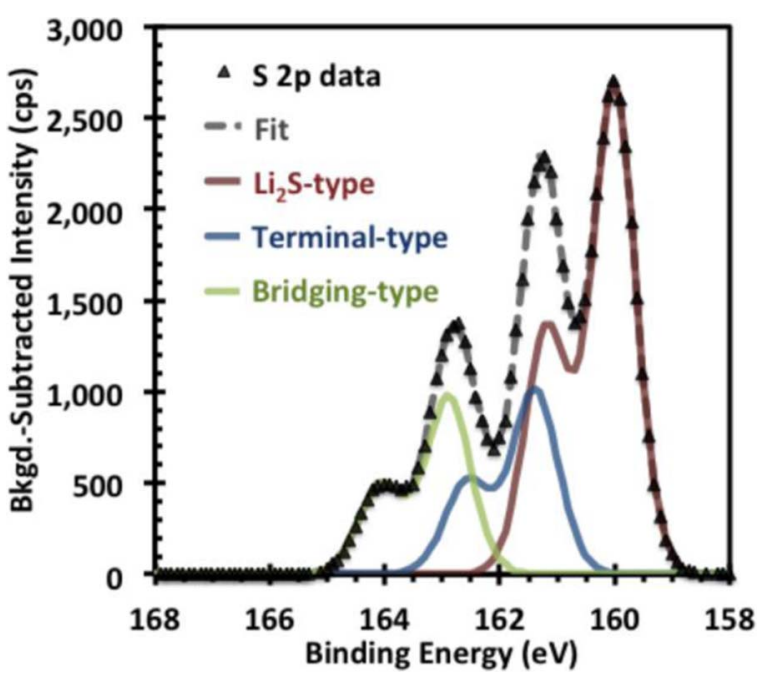

Figure 2. XPS sulfur $2 p$ region spectrum of the synthesized $\mathrm{Li}_{2} \mathrm{~S}_{\mathrm{x}}$ after initial filtration from THF. The background-subtracted data points are indicated with triangular markers. The deconvolved $\mathrm{Li}_{2} \mathrm{~S}$-type (red line), terminal-type (blue line), and bridging-type (green line) signals are plotted along with the fit (dashed gray line) from summing the deconvoluted signals.

atom and one other sulfur atom. This was the only type of sulfur atom that would be present in $\mathrm{Li}_{2} \mathrm{~S}_{2}$, while all higher-order linear polysulfides would have two of these sulfurs at the termini of their polysulfide chains, regardless of chain length. The shift to higher binding energy was consistent with the intermediate anionic character of these atoms, ${ }^{33,34}$ with theoretical studies putting the effective charge of terminal sulfur atoms between -0.90 (in $\mathrm{Li}_{2} \mathrm{~S}_{3}$ ) and -0.77 (in $\left.\mathrm{Li}_{2} \mathrm{~S}_{6}\right){ }^{35}$ From the theoretical trend, the charge on terminal sulfur atoms in $\mathrm{Li}_{2} \mathrm{~S}_{2}$ can be assumed to be more negative than -0.90 , though still significantly more covalent than in $\mathrm{Li}_{2} \mathrm{~S}$.

Finally, the signal recorded at the highest binding energy, $162.9 \mathrm{eV}$, was ascribed to "bridging" sulfur, i.e., a sulfur atom that is bonded to two other sulfur atoms in the middle of a polysulfide chain. Bridging sulfurs can thus only be present in higher-order polysulfides. The higher binding energy was associated with the significant covalent character expected for bridging sulfur atoms, with theoretical studies putting the effective charge on the various bridging sulfurs in linear $\mathrm{Li}_{2} \mathrm{~S}_{4}$ and $\mathrm{Li}_{2} \mathrm{~S}_{6}$ between -0.17 and $-0.11{ }^{35}$ The distribution of some additional electron density onto the bridging sulfurs accounted for the binding energy still being significantly lower than for neutral sulfur in elemental $\mathrm{S}_{8}$ rings, for which the binding energy is above $164.0 \mathrm{eV}^{33}$ Indeed, the lack of any spectral intensity above $165 \mathrm{eV}$ confirmed that no elemental sulfur existed in the synthesized sample, as the neutral sulfur would display a S $2 \mathrm{p}_{1 / 2}$ peak at $\sim 165.3 \mathrm{eV}$. Additionally, the lack of any signal above $166 \mathrm{eV}$ confirmed there are no sulfite $\left(\mathrm{R}-\mathrm{SO}_{3}{ }^{2-}\right.$ ) or sulfate $\left(\mathrm{R}-\mathrm{SO}_{4}{ }^{2-}\right)$ species present, as these peaks appear above $166 \mathrm{eV}$ and $167 \mathrm{eV}$, respectively. ${ }^{33}$ The XPS S 2p spectrum for elemental sulfur can be seen in Figure S1(b) of the Supporting Information. The XPS spectrum for the synthesized product indicated the presence of a small quantity of carbon and oxygen, as seen in Figures S1(d)-(e), consistent with a thin organic contaminant layer on the surface of the sample. ${ }^{33}$

It should be noted that the ranges in effective charge on the $\mathrm{Li}_{2} \mathrm{~S}$ type, terminal-type, and bridging-type sulfur atoms can be separated into three distinct groups, corresponding to each type. Variation within a group would then manifest itself as a broadening of the FWHM for that particular signal. As there is only one specific " $\mathrm{Li}_{2} \mathrm{~S}$-type" environment, there should be the least broadening, and, as predicted, the $\mathrm{Li}_{2} \mathrm{~S}$-type peak had the smallest FWHM. Further deconvolution of the three signals to differentiate individual terminal or bridging sulfur atoms was not possible given the small predicted binding energy shifts and the resolution limits of the XPS technique. 
The Li 1s spectrum presented in Figure S1(c) of the Supporting Information was fit with two arbitrary peaks to measure the integrated peak area for the purpose of elemental quantification. From the lithium and sulfur spectra, the overall stoichiometry of the product determined by XPS was $\mathrm{Li}_{2} \mathrm{~S}_{1.4}$. This value confirmed that sulfur was preferentially lost to the synthesis and initial filtration in THF, as the initial $1: 1$ lithium : sulfur stoichiometry was not preserved. Deconvolution of the sulfur region indicated that the sulfur atoms in the synthesized sample were comprised of 56.4 atom $\% \mathrm{Li}_{2} \mathrm{~S}$-type, 22.5 atom\% terminal-type, and 21.2 atom\% bridging-type. Using this quantification and a basis set of potential sulfide molecules, namely $\mathrm{Li}_{2} \mathrm{~S}, \mathrm{Li}_{2} \mathrm{~S}_{2}$, and $\mathrm{Li}_{2} \mathrm{~S}_{6}$ (the solid polysulfide proposed by Cuisinier et al.), ${ }^{6}$ the sulfide speciation was determined. This method identified the product as being $83.4 \mathrm{~mol} \% \mathrm{Li}_{2} \mathrm{~S}, 8.8 \mathrm{~mol} \% \mathrm{Li}_{2} \mathrm{~S}_{2}$, and $7.8 \mathrm{~mol} \% \mathrm{Li}_{2} \mathrm{~S}_{6}$. The stoichiometry of this speciation, determined solely from the deconvolved sulfur signal, was $\mathrm{Li}_{2} \mathrm{~S}_{1.5}$, in good agreement with the value calculated from the lithium and sulfur regions as a whole. The small discrepancy can be accounted for if the simple three-element basis set was expanded such that a small fraction of the bridging sulfur atoms was ascribed to intermediate-length polysulfide-type species $\left(\mathrm{Li}_{2} \mathrm{~S}_{3}\right.$, $\mathrm{Li}_{2} \mathrm{~S}_{4}$, or $\mathrm{Li}_{2} \mathrm{~S}_{5}$ ), instead of only to $\mathrm{Li}_{2} \mathrm{~S}_{6}$. The discrepancy could also arise due to systemic errors arising from the use of semi-quantitative standard elemental RSFs.

$\mathrm{Li}_{2} \mathrm{~S}_{6}$ and other higher-order polysulfides are known to be highly soluble in the organic solvents used as Li-S battery electrolytes. ${ }^{9}$ The aim of this work was to isolate the electrochemical behavior of insoluble polysulfide-type species, so the higher order polysulfides were extracted using a filtration scheme. Figure 3 a shows the liquid filtrates collected from nine sequential vacuum filtrations of a sample of the synthesized powder. The characteristic yellow color of polysulfide solutions was clearly visible in the initial filtrates, becoming light green, and then clear by the fifth collected filtrate. UV-vis spectroscopy was used to track the progress of the filtration process. Several features in the absorption spectrum were seen to clearly disappear with filtration as shown in Figures $3 b-3 c$, including a broad peak at $\sim 620 \mathrm{~nm}$ that is characteristic of the $\mathrm{S}_{3} \bullet^{-}$radical which results from dissociation of $\mathrm{S}_{6}{ }^{2-}$. Other peaks were tentatively assigned based on reported absorption peaks in TEGDME, such as the peak at $\sim 255 \mathrm{~nm}$ which corresponds to the $\mathrm{S}_{6}{ }^{2-}$ species. The absorption intensity between 360 and $530 \mathrm{~nm}$ was ascribed to several higher-order polysulfide species, including $\mathrm{S}_{4}{ }^{2-}, \mathrm{S}_{5}{ }^{2-}$, and $\mathrm{S}_{6}{ }^{2-} \cdot{ }^{9}$ (Refer to Figure $\mathrm{S} 2$ of the Supporting Information for a reference spectrum recorded for a solution of $\mathrm{Li}_{2} \mathrm{~S}_{6}$ and for a more detailed comparison of the changes in absorption spectra between individual filtrates.) By the eighth and ninth filtration, the absorption spectra were consistent, with no observed changes with additional vacuum filtration. Two features remained, a pronounced peak at $\sim 265 \mathrm{~nm}$ and a smaller shoulder at $\sim 320 \mathrm{~nm}$. These peaks were generally consistent with the peaks at $\sim 270$ and $\sim 340 \mathrm{~nm}$ reported for, respectively, $\mathrm{S}_{2}{ }^{2-}$ and $\mathrm{S}_{3}{ }^{2-}$ in TEGDME. ${ }^{9}$ While this result could be consistent with the sparing solubility of $\mathrm{Li}_{2} \mathrm{~S}_{2}$ and some persistent $\mathrm{Li}_{2} \mathrm{~S}_{3}$, a third feature of the absorption spectra suggested to us that these peaks were consistent with absorption from $\mathrm{Li}_{2} \mathrm{~S}_{2}$ and $\mathrm{Li}_{2} \mathrm{~S}_{3}$ type species in suspended sulfide particles that had passed through the filter into the filtrate. Figure $3 \mathrm{~d}$ showed the appearance of an interference pattern between 686 and $706 \mathrm{~nm}$ that is a characteristic effect arising from forward scattering by suspended small particles. ${ }^{36}$ These effects are suppressed if there is high overall absorption, ${ }^{36}$ so they did not appear until later filtrations when the absorption peaks at higher wavelengths had disappeared. These results indicated that after filtration, in addition to the main $\mathrm{Li}_{2} \mathrm{~S}$ portion, $\mathrm{Li}_{2} \mathrm{~S}_{2}$ and a small amount of $\mathrm{Li}_{2} \mathrm{~S}_{3}$-type species remained in the solid state.

XPS spectra collected from the $\mathrm{Li}_{2} \mathrm{~S}_{\mathrm{x}}$ powder obtained after extended filtration agreed with this result. Figure 4 a shows the $S 2 p$ signal, with deconvolved peaks for the three types of sulfur atoms identified in $\mathrm{Li}_{2} \mathrm{~S}_{\mathrm{x}}$ species. The bridging-type peak had almost disappeared, while a comparatively small decrease was observed in the intensity of the terminal-type peak. The powders were sputtered to confirm that the presence of polysulfide-type species was not confined to the immediate surface of the particles. Refer to Figure S3
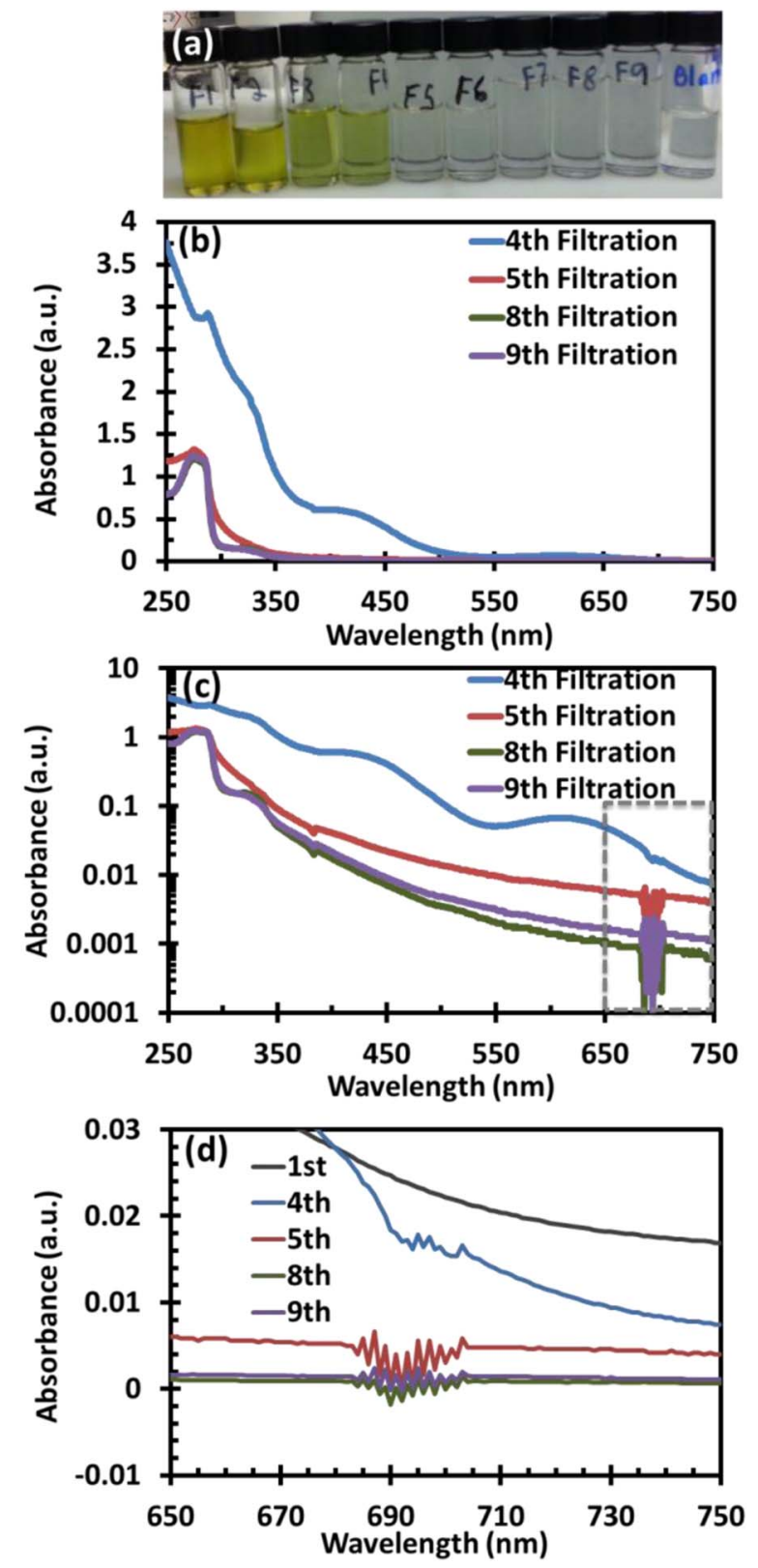

Figure 3. (a) Photograph of the observed color change with sequential filtrations, with the first filtration on the left and the $9^{\text {th }}$ filtration second from the right. The rightmost vial contains the DME/DOL blank solution. (b) Linear scale and (c) log scale UV-vis spectra of the filtrate collected after selected filtrations $\left(4^{\text {th }}-\right.$ blue, $5^{\text {th }}$ red, $8^{\text {th }}-$ green, $9^{\text {th }}-$ purple $)$ of the synthesized $\mathrm{Li}_{2} \mathrm{~S}_{\mathrm{x}}$. The expanded region in (d) shows the interference patterns apparent in later filtrations. The magnified region is identified by the dashed gray rectangle in (c).

of the Supporting Information to examine the effect of sputtering on the XPS spectra and for a discussion of possible sputtering-induced damage. After sputtering, quantification of the deconvolved sulfur peaks implied that the sulfur atoms were 82.0 atom $\% \mathrm{Li}_{2} \mathrm{~S}$-type, 16.5 atom\% terminal-type, and 1.6 atom\% bridging-type. Using the same three-species basis set as in the original XPS analysis implied sulfide speciation of $90.9 \mathrm{~mol} \% \mathrm{Li}_{2} \mathrm{~S}, 8.7 \mathrm{~mol} \% \mathrm{Li}_{2} \mathrm{~S}_{2}$, and $0.4 \mathrm{~mol} \% \mathrm{Li}_{2} \mathrm{~S}_{6}$. This result reinforced the conclusion that higher-order polysulfides were removed by filtration, while $\mathrm{Li}_{2} \mathrm{~S}_{2}$-type species were insoluble and were retained. The UV-vis results implied that a better analysis of the post-filtration solid would be as a mix of $\mathrm{Li}_{2} \mathrm{~S}, \mathrm{Li}_{2} \mathrm{~S}_{2}$, and $\mathrm{Li}_{2} \mathrm{~S}_{3}$ 

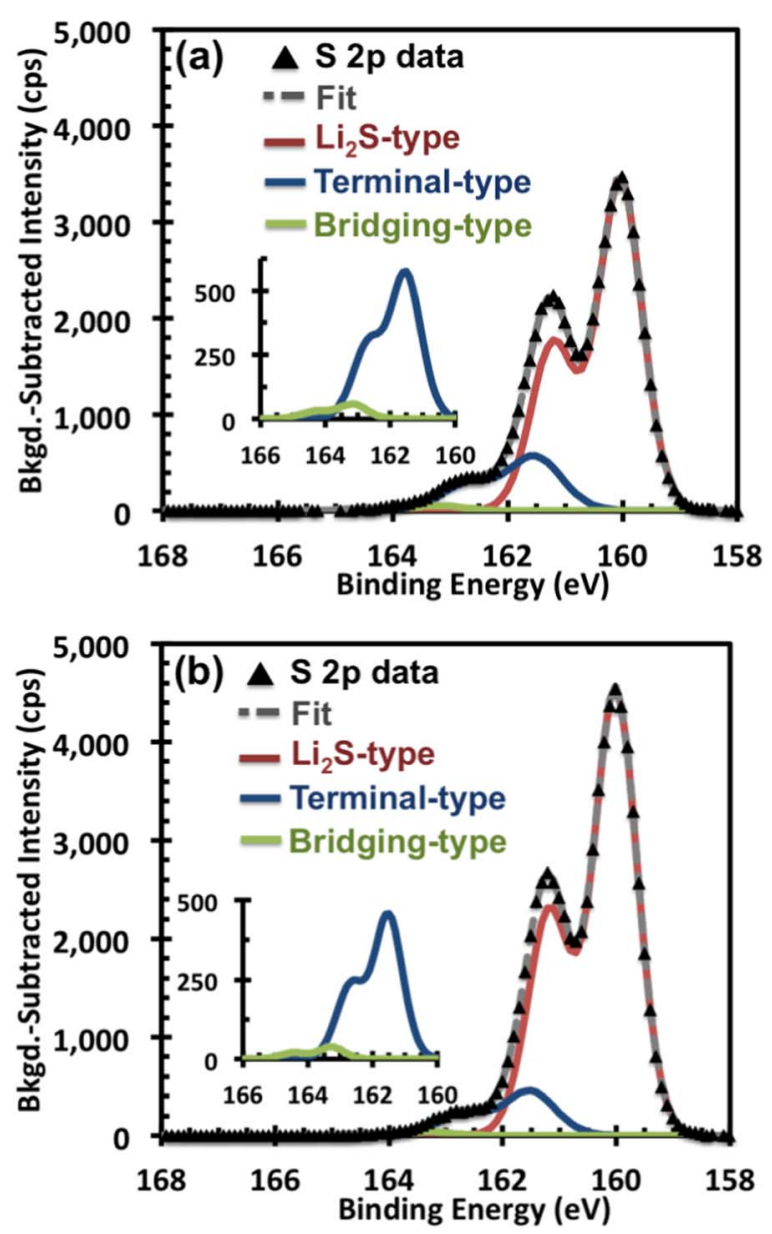

Figure 4. Background-subtracted, post-sputtering XPS sulfur $2 p$ spectra for (a) filtered, synthesized $\mathrm{Li}_{2} \mathrm{~S}_{\mathrm{x}}$ and (b) commercial, reference $\mathrm{Li}_{2} \mathrm{~S}$. The deconvolved $\mathrm{Li}_{2} \mathrm{~S}$-type (red line), terminal-type (blue line), and bridging-type (green line) signals are plotted along with the fit (dashed gray line) from summing the deconvolved signals. The inset of each figure isolates the terminal-type and bridging-type signals.

type species. With this alternative basis, the implied speciation was $90.9 \mathrm{~mol} \% \mathrm{Li}_{2} \mathrm{~S}, 7.4 \mathrm{~mol} \% \mathrm{Li}_{2} \mathrm{~S}_{2}$, and $1.7 \mathrm{~mol} \% \mathrm{Li}_{2} \mathrm{~S}_{3}$.

In addition, spectra collected on nominally pure $\mathrm{Li}_{2} \mathrm{~S}$ obtained from commercial vendors, intended as a reference for the $\mathrm{Li}_{2} \mathrm{~S} \mathrm{~S} 2 \mathrm{p}$ XPS peak, exhibited intensity in a region consistent with small amounts of polysulfide-type impurities. Refer to the Supporting Information for a discussion of measures taken to ensure the quality of the XPS data and to exclude possible sources of contamination. A previous report identified up to $2 \mathrm{wt} \%$ of soluble polysulfide impurities in a commercial $\mathrm{Li}_{2} \mathrm{~S}$ sample. ${ }^{37}$ After sputtering, which removed a sulfite surface contaminant species (cf. Figure S3(d) of the Supporting Information), the XPS S 2p data in Figure 4b was collected. The spectrum could be deconvolved and quantified, suggesting to us that the sulfur atoms in "reference" $\mathrm{Li}_{2} \mathrm{~S}$ were 88.8 atom $\% \mathrm{Li}_{2} \mathrm{~S}$-type, 10.4 atom\% terminal-type, and 0.8 atom\% bridging-type. Using the initial sulfide basis set, this speciation indicated that the reference $\mathrm{Li}_{2} \mathrm{~S}$ sample was comprised of $94.5 \mathrm{~mol} \% \mathrm{Li}_{2} \mathrm{~S}, 5.3 \mathrm{~mol} \% \mathrm{Li}_{2} \mathrm{~S}_{2}$, and $0.2 \mathrm{~mol} \% \mathrm{Li}_{2} \mathrm{~S}_{6}$. If the conclusion from the UV-vis data on the filtered, synthesized sample was applied here, the speciation was $94.5 \mathrm{~mol} \% \mathrm{Li}_{2} \mathrm{~S}, 4.7$ $\mathrm{mol} \% \mathrm{Li}_{2} \mathrm{~S}_{2}$, and $0.8 \mathrm{~mol} \% \mathrm{Li}_{2} \mathrm{~S}_{3}$. The atomic speciation determined by XPS for the various samples is summarized in Table I.

This result indicated that nominally pure $\mathrm{Li}_{2} \mathrm{~S}$ actually had some fraction of sulfur-sulfur bonding, and could indeed be electrochemically reduced, as will be discussed in the electrochemical characterization section of this work. We discuss in the Supporting
Table I. Comparison of the XPS quantification for the synthesized $\mathrm{Li}_{2} \mathrm{~S}_{\mathrm{x}}$ sample before and after filtration from DME/DOL, and a reference commercial $\mathrm{Li}_{2} \mathrm{~S}$ sample.

\begin{tabular}{cccc} 
Sulfur Species & $\begin{array}{c}\text { Synthesized } \\
\mathrm{Li}_{2} \mathrm{~S}_{\mathrm{x}}, \mathrm{THF} \\
\text { filtration only }\end{array}$ & $\begin{array}{c}\text { Synthesized } \\
\mathrm{Li}_{2} \mathrm{~S}_{\mathrm{x}}, \mathrm{DME} / \mathrm{DOL} \\
\text { filtered and } \\
\text { sputtered }\end{array}$ & $\begin{array}{c}\text { Commercial } \\
\text { reference } \mathrm{Li}_{2} \mathrm{~S}, \\
\text { sputtered }\end{array}$ \\
\hline Li $i_{2}$ S-type & 56.4 at.\% & 82.0 at.\% & 88.8 at. $\%$ \\
Terminal-type & 22.5 at.\% & 16.5 at.\% & 10.4 at.\% \\
Bridging-type & 21.2 at.\% & 1.6 at. $\%$ & 0.8 at.\% \\
$\mathrm{Li}_{2} \mathrm{~S}$ : Terminal & $2.5: 1$ & $5: 1$ & $8.5: 1$ \\
Ratio & & $116 \mathrm{mAh} \mathrm{g}^{-1}$ & $70 \mathrm{mAh} \mathrm{g}^{-1}$ \\
Discharge & $418 \mathrm{mAh} \mathrm{g}^{-1}$ & & \\
Capacity & & &
\end{tabular}

Information that the product specification for commercially-obtained $\mathrm{Li}_{2} \mathrm{~S}$ describes its physical appearance as "white to yellow" or "beige" and note that the specified purity was based on the presence of trace metals. Given that the large bandgap calculated ${ }^{10,18,38}$ for $\mathrm{Li}_{2} \mathrm{~S}$, $\sim 3.5 \mathrm{eV}-3.7 \mathrm{eV}$, would normally imply that an ionic solid would not absorb visible light and would thus be white, we hypothesized that existence of an off-white or yellow color in $\mathrm{Li}_{2} \mathrm{~S}$ samples was indicative of the presence of polysulfide-type impurities. Theoretical calculations suggest $\mathrm{Li}_{2} \mathrm{~S}_{2}$ would have an indirect bandgap of $\sim 1.8 \mathrm{eV} .{ }^{10}$ As can be seen in Figure S5 of the Supporting Information, the deep yellow color of our synthesized material disappeared with filtration of the highly colored higher-order polysulfides, but a light, straw yellow color was retained. This is consistent with the presence of a greater concentration of insoluble polysulfide-type species in the synthesized sample than in reference $\mathrm{Li}_{2} \mathrm{~S}$.

The quantification of polysulfide species present in a solid sample allowed for the calculation of a theoretical discharge capacity (as listed in Table I) in an electrochemical cell if all of the polysulfides were reduced to $\mathrm{Li}_{2} \mathrm{~S}$. For the as-synthesized sample after only filtration from THF, the predicted capacity was $\sim 418 \mathrm{mAh} \mathrm{g}^{-1}$. As can be seen in Figure 5, this was in excellent agreement with the capacity observed when the powder was assembled into a cell on a CNF current collector and galvanostatically discharged to $1.8 \mathrm{~V}$ vs. $\mathrm{Li} / \mathrm{Li}^{+}$. This result supported the elemental quantification performed using XPS data.

With subsequent filtrations, the capacity can be seen to decrease in Figure 5, consistent with the loss of soluble, easily-reduced higherorder polysulfides. It should also be noted that the discharge curves in

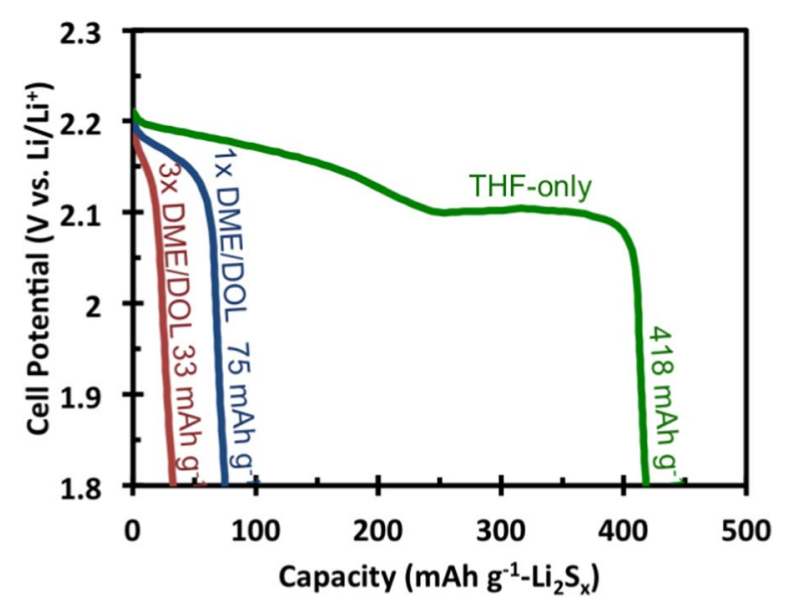

Figure 5. Galvanostatic discharge curves at $50 \mu \mathrm{A} \mathrm{cm}^{-2}$ to $1.8 \mathrm{~V}$ vs. $\mathrm{Li}^{2} / \mathrm{Li}^{+}$ for the synthesized $\mathrm{Li}_{2} \mathrm{~S}_{\mathrm{x}}$ powder after only THF filtration (green line), one filtration from DME/DOL (blue line), and three filtrations from DME/DOL (red line). 

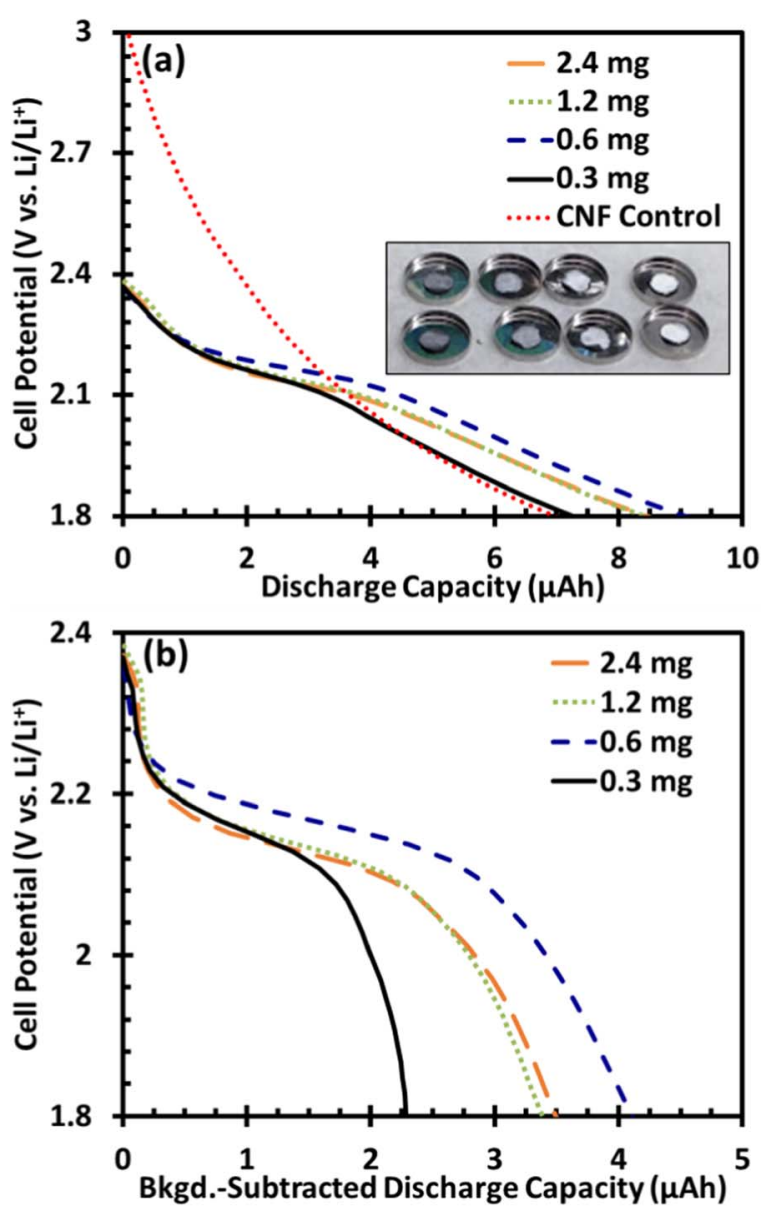

Figure 6. Galvanostatic discharge curves at $50 \mu \mathrm{A} \mathrm{cm}{ }^{-2}$ to $1.8 \mathrm{~V} \mathrm{vs.} \mathrm{Li} / \mathrm{Li}^{+}$ for different loadings, from $0 \mathrm{mg}$ (control, in red) to $2.4 \mathrm{mg}(0.3 \mathrm{mg}$ - black, $0.6 \mathrm{mg}$ - blue, $1.2 \mathrm{mg}$ - green, $2.4 \mathrm{mg}$ - orange) of commercial reference $\mathrm{Li}_{2} \mathrm{~S}$ (a) before and (b) after background subtraction. The inset of (a) shows the appearance of the $\mathrm{Li}_{2} \mathrm{~S}$-loaded $\mathrm{CNF}$ paper current collectors with increasing loading (from left to right).

Figure 5 were at a fixed $50 \mu \mathrm{A} \mathrm{cm}^{-2}$. Thus as polysulfides were removed, at a fixed loading, the effective discharge rate for the remaining reducible species was increasing (from $\sim \mathrm{C} / 13$ for the as-synthesized sample to $\sim \mathrm{C} / 3$ for the filtered samples).

Figure 6a shows the galvanostatic discharge curves for different loadings of commercial reference $\mathrm{Li}_{2} \mathrm{~S}$ at $50 \mu \mathrm{A} \mathrm{cm}^{-2}$. As can be seen, the absolute discharge capacity of the cell saturated at a loading above $0.6 \mathrm{mg} \mathrm{cm}^{-2}$. Indeed, the specific capacity was at a maximum for the lowest loading tested, $0.3 \mathrm{mg} \mathrm{cm}^{-2}$, despite somewhat paradoxically, being discharged at the highest gravimetric specific rate. This result was consistent with the reduction being limited by the available surface area of the current collector.

As can also be seen in Figure 6a, the control cell, consisting of a CNF current collector with no sulfide loading, exhibited a discharge capacity, though no plateau. This plateau-free discharge capacity was the result of electrolyte reduction on the $\mathrm{CNF}$ surface. A low surface area nickel foam current collector was explored, which exhibited little background capacity. However negligible discharge capacity was also observed in cells loaded with $\mathrm{Li}_{2} \mathrm{~S}_{\mathrm{x}}$ due to the lack of available surface area for polysulfide reduction. Consult the Supporting Information Figure S6 for a more detailed look at the role of current collector surface area on this control capacity.

In order to isolate the reduction of sulfide species from this background electrolyte reduction phenomenon, we performed a rudimentary background subtraction. For each differential voltage step in the sample discharge data, we subtracted the corresponding differential
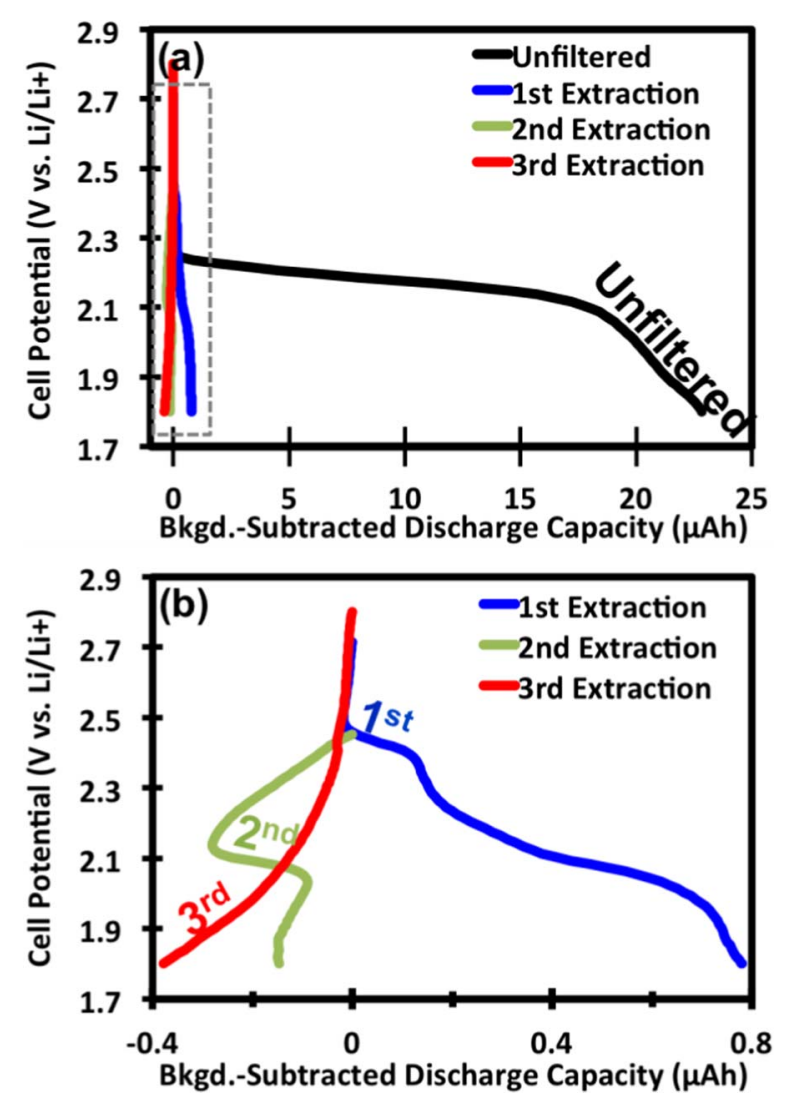

Figure 7. Background-subtracted galvanostatic discharge curves at $50 \mu \mathrm{A} \mathrm{cm} \mathrm{cm}^{-2}$ for catholytes prepared from the supernatant solution above synthesized $\mathrm{Li}_{2} \mathrm{~S}_{\mathrm{X}}$ after sequential polysulfide extractions with DME/DOL. (a) Includes the capacity (black line) observed for the solution above the as-synthesized sample before any further polysulfide extraction in DME/DOL. (b) Shows an expanded view of the area indicated by the gray box in (a) and includes only the $1^{\text {st }}$ (blue), $2^{\text {nd }}$ (green), and $3^{\text {rd }}$ (red) sequential extractions.

capacity for the same voltage step in the control data. The backgroundsubtracted curves for the reference $\mathrm{Li}_{2} \mathrm{~S}$ galvanostatic discharge experiments are presented in Figure 6b. As can be seen, the plateaus in the background-subtracted data were significantly sharper and the long sloping tails at lower potentials due to electrolyte reduction were largely removed.

It is important to point out that this technique actually overcorrects the data due to its simplistic nature. In the control cells, the entire surface area of the CNF current collectors was available for electrolyte reduction. In the sample cells, some fraction of the CNFs was covered with the solid slurry-cast $\mathrm{Li}_{2} \mathrm{~S}_{\mathrm{x}}$ powder, and as a result, less CNF surface area was available for electrolyte reduction. The net result was that subtracting $100 \%$ of the corresponding control data actually slightly overcorrected for the background discharge capacity. This manifested itself in a very small $(<0.5 \mu \mathrm{Ah})$ anomalous negative discharge "capacity" in very low loading cells, as seen in the background-subtracted galvanostatic discharge curves for postfiltration $\mathrm{Li}_{2} \mathrm{~S}_{\mathrm{x}}$ in Figure 7 . While a more sophisticated model can correct for this, it served to overcomplicate the analysis and the simple model was adequate for isolating the sulfide reduction plateaus in $\mathrm{Li}_{2} \mathrm{~S}_{\mathrm{x}}$ samples.

The observation that commercial $\mathrm{Li}_{2} \mathrm{~S}$ samples contained polysulfide-type impurities has important implications for the analysis of $\mathrm{Li}-\mathrm{S}$ cells fabricated with $\mathrm{Li}_{2} \mathrm{~S}$ cathodes as the starting material in place of sulfur. A large overpotential has been observed in the literature when first attempting to charge $\mathrm{Li}_{2} \mathrm{~S} .{ }^{39}$ This overpotential has been ascribed to the need to form a new polysulfide phase and has been shown to be influenced by the presence (or introduction) 
of sulfur-sulfur bonding in the $\mathrm{Li}_{2} \mathrm{~S}$ particle surface. ${ }^{29,39}$ The prior report identifying soluble polysulfide impurities in commercial $\mathrm{Li}_{2} \mathrm{~S}$ samples suggested to the authors that they played an integral role in the oxidation mechanism of $\mathrm{Li}_{2} \mathrm{~S}$ during charge. ${ }^{37}$ It is likely that the degree of sulfur-sulfur bonding already present as an impurity in $\mathrm{Li}_{2} \mathrm{~S}$ may influence this behavior, including the size of the overpotential required to charge the material. Indeed, given the mechanistic difficulty of forming $\mathrm{Li}_{2} \mathrm{~S}_{4}$ (the first soluble species observed when charging $\mathrm{Li}-\mathrm{S}$ batteries) from $\mathrm{Li}_{2} \mathrm{~S},{ }^{6,9}$ it is worth investigating if pure $\mathrm{Li}_{2} \mathrm{~S}$ can be charged at all in the absence of polysulfide-type impurities.

In order to confirm that none of the observed discharge capacity in the synthesized $\mathrm{Li}_{2} \mathrm{~S}_{\mathrm{x}}$ samples was due to residual soluble higher-order polysulfides, a tailored electrochemical monitoring approach was applied to the filtration scheme. The liquid filtrate could be collected, prepared as a catholyte, and analyzed electrochemically to determine the polysulfide concentration. A schematic depiction of this approach is provided in Figure S7 of the Supporting Information. Any soluble higher-order polysulfides in the solid powder went into solution when mixed with DME/DOL and could thus be reduced when the solution was discharged. For typical vacuum filtrations with a fixed amount of solution and no particle pass-through, this approach was quantitative and the amount of polysulfides extracted via filtration could be calculated for the starting solid powder. As is presented in Table S1 of the Supporting Information, these values agreed well with the $\mathrm{Li}_{2} \mathrm{~S}_{6}$ concentration predicted by XPS for the first two filtrations. After two filtrations, the grinding action of the magnetic stir bar acted to reduce the particle size below $100 \mathrm{~nm}$ and solid particles passed through the filter, adding to the observed discharge capacity of the filtrate.

Beyond this point, sequential polysulfide extractions proceeded simply by mixing the powder with a volume of DME/DOL and allowing the solid to sediment with no filtration. The supernatant extracted after sedimentation was analyzed for residual reducible polysulfides. As can be seen in Figure 7, the size of the reduction plateaus decreased with each subsequent polysulfide extraction. After the third "filter-free" extraction, no plateaus existed in the discharge curve, confirming that all soluble polysulfides had been removed from the solid powder.

After all the soluble polysulfides were confirmed to be removed, the remaining solid $\mathrm{Li}_{2} \mathrm{~S}_{\mathrm{x}}$ powder $\left(0.2 \mathrm{mg} \mathrm{cm}^{-2}\right.$ nominal loading) was discharged galvanostatically at $100 \mu \mathrm{A} \mathrm{cm}^{-2}$ along with a commercial $\mathrm{Li}_{2} \mathrm{~S}$ reference (also $0.2 \mathrm{mg} \mathrm{cm}^{-2}$ nominal loading) and a $\mathrm{CNF}$ control. The commercial $\mathrm{Li}_{2} \mathrm{~S}$ reference was first magnetically stirred in DME/DOL to both wash the material and grind down the particle size. The solution was then vacuum-filtered through a $100 \mathrm{~nm}$ nylon filter and the particles that passed through the filter were collected from the liquid filtrate after sedimentation. The commercial $\mathrm{Li}_{2} \mathrm{~S}$ reference was thus washed and nano-sized in an analogous fashion to the synthesized, polysulfide-extracted $\mathrm{Li}_{2} \mathrm{~S}_{\mathrm{x}}$ powder. The raw and background-subtracted discharge curves are presented in Figure 8. At this rate, only a small sloping discharge plateau $(\sim 0.3 \mu$ Ah wide) was observable in the $\mathrm{Li}_{2} \mathrm{~S}$ reference cell. The $3.3 \mu \mathrm{Ah}$ discharge plateau at $\sim 2.1 \mathrm{~V}$ vs. $\mathrm{Li} / \mathrm{Li}^{+}$for the synthesized $\mathrm{Li}_{2} \mathrm{~S}_{\mathrm{x}}$ sample corresponded to $16 \mathrm{mAh} \mathrm{g}{ }^{-1}-\mathrm{Li}_{2} \mathrm{~S}_{\mathrm{x}}$, approximately $14 \%$ of the capacity predicted by XPS (cf. Table I). However, the discharge rate, chosen to limit the degree of background electrolyte reduction, translated to an effective rate of $>2 \mathrm{C}$ based on the XPS-determined concentration of polysulfides in the synthesized powder. That any sulfide reduction was observed at this high a rate was strong evidence that solid polysulfides were indeed reducible in the absence of electrolyte solubility. This result, in combination with the surface area limitation for sulfide loading observed in Figure 6, suggested to us that the reduction was confined to regions where the sulfur-sulfur bonds were in intimate contact with the conductive current collector.

The significantly smaller discharge plateau observed in the commercial $\mathrm{Li}_{2} \mathrm{~S}$ was consistent with this result, as the lower concentration of polysulfide-species in the commercial reference would result in more blocking of the sulfur-sulfur bonds by non-reducible $\mathrm{Li}_{2} \mathrm{~S}$ species. We hypothesize that this effect could be amplified by increased electronic conductivity and/or atomic mobility in samples
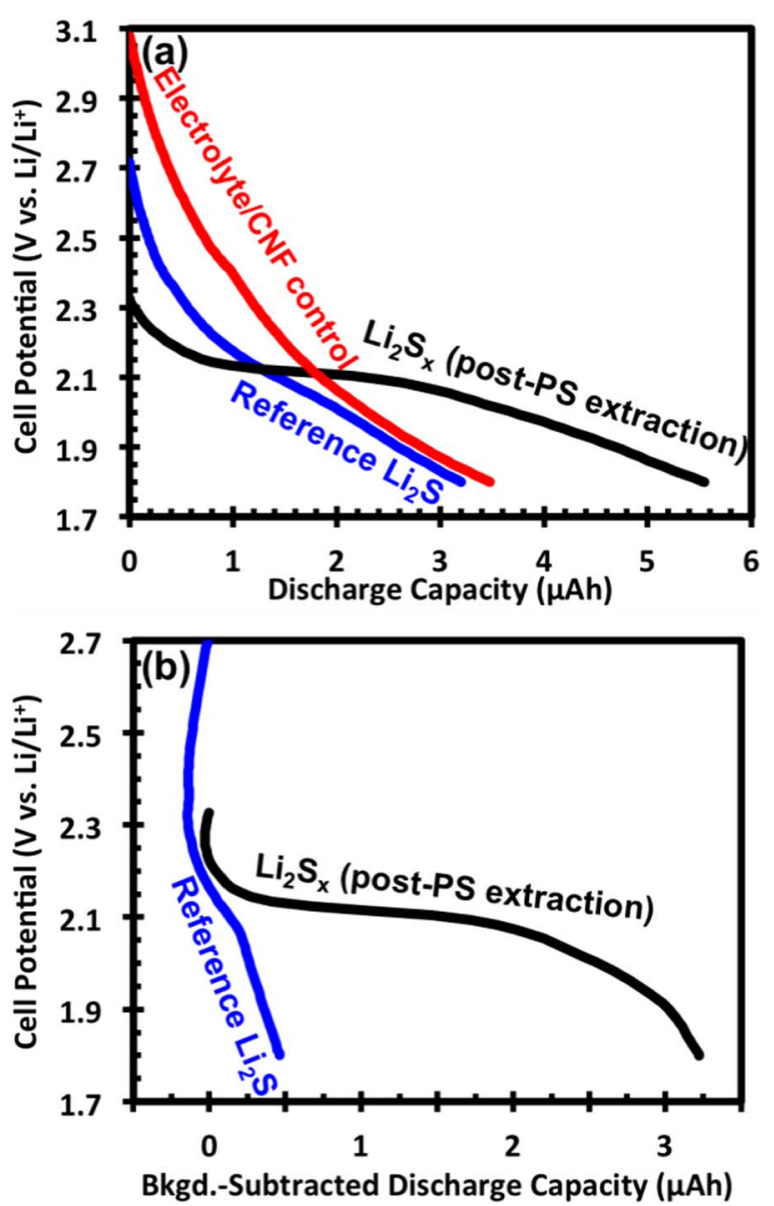

Figure 8. (a) Raw and (b) background-subtracted galvanostatic discharge curves at $100 \mu \mathrm{A} \mathrm{cm}^{-2}$ to $1.8 \mathrm{~V} \mathrm{vs}$. Li/Li ${ }^{+}$for CNF paper control (red line), commercial $\mathrm{Li}_{2} \mathrm{~S}$ (blue line), and synthesized $\mathrm{Li}_{2} \mathrm{~S}_{\mathrm{X}}$ after complete extraction of soluble polysulfides (black line).

with higher polysulfide concentrations. Higher mobility could increase the effective distance from the current collector for which sulfur-sulfur bonds are reducible at a given rate. These effects could account for the significant difference in the size of the reduction plateau for the synthesized sample versus the commercial $\mathrm{Li}_{2} \mathrm{~S}$. There could additionally be a difference in particle size between the commercial $\mathrm{Li}_{2} \mathrm{~S}$ and synthesized samples. While both samples passed through $100 \mathrm{~nm}$ pore size filters, the multiple filtration/extraction cycles for the synthesized sample may have reduced the particle size further, resulting in a greater specific surface area than the commercial $\mathrm{Li}_{2} \mathrm{~S}$. This would increase the contact area between the sample and the current collector for polysulfide reduction. As shown in Figure S8 of the Supporting Information, the discharge plateau for a cell prepared with commercial $\mathrm{Li}_{2} \mathrm{~S}$ that had not been rinsed or nanosized was significantly smaller $(\sim 0.1 \mu \mathrm{Ah})$, consistent with these surface area effects.

This result has an important implication for the possible reaction mechanisms that have been proposed for Li-S batteries. While these experiments cannot prove that $\mathrm{Li}_{2} \mathrm{~S}_{2}$ forms during discharge of a $\mathrm{Li}-\mathrm{S}$ battery, they do show that if it does form, provided it does so on a conductive surface, it can be readily reduced to $\mathrm{Li}_{2} \mathrm{~S}$. Thus reduction pathways that form $\mathrm{Li}_{2} \mathrm{~S}_{2}$ as the first solid product are not inherently limited from reaching the full $1672 \mathrm{mAh} \mathrm{g}^{-1}$ theoretical capacity. Our results also emphasize the importance of solid sulfide deposition morphology, as formation of $\mathrm{Li}_{2} \mathrm{~S}_{2}$ at any significant distance from the current collector would not be electrochemically accessible and would thus contribute to capacity loss. 


\section{Conclusions}

We have demonstrated through spectroscopic and electrochemical means that the direct reaction of lithium and sulfur in liquid ammonia at low temperature produces a product that, while predominantly $\mathrm{Li}_{2} \mathrm{~S}$, is enriched in solid polysulfide species. Additionally, we have shown that higher-order electrolyte-soluble polysulfide species can be extracted, while retaining lower-order $\left(\mathrm{Li}_{2} \mathrm{~S}_{\mathrm{x}}, \mathrm{x} \leq 3\right)$ insoluble polysulfide species. A filtered product that was $\sim 91 \mathrm{~mol} \% \mathrm{Li}_{2} \mathrm{~S}$ and $\sim 9 \mathrm{~mol} \%$ insoluble polysulfide-type species was obtained. It was shown that these insoluble polysulfide species could be electrochemically reduced in a typical lithium-sulfur battery environment. The reduction of insoluble polysulfides appeared to be limited to sulfur-sulfur bonds that were in intimate contact with a conductive current collector. Finally, we demonstrated that nominally pure $\mathrm{Li}_{2} \mathrm{~S}$ samples obtained commercially contain small fractions (up to $5 \mathrm{~mol} \%$ ) of polysulfide-type impurities, which were confirmed to be electrochemically reducible.

\section{Acknowledgments}

This work was supported by the United States Department of Energy, Office of Basic Energy Sciences, Division of Materials Science and Engineering under award DE-SC0005397. M. K. was supported by the National Science Foundation Graduate Research Fellowship Program (GRFP) under grant number DGE-1110007. K. G. acknowledges the Belgian American Educational Foundation (BAEF) for a postdoctoral fellowship.

C. W. B. and K. G. are grateful to the Institute for Basic Science (IBS-R019-D1) and the BK21 Plus Program as funded by the Ministry of Education and the National Research Foundation of Korea for their support. The authors thank Dr. Hugo Celio, Dr. Chenxi Zu, and Craig Milroy for their assistance performing XPS experiments and for valuable discussions.

\section{References}

1. X. Ji, K. T. Lee, and L. F. Nazar, Nat Mater, 8, 500 (2009).
2. A. Manthiram, Y. Fu, and Y.S. Su, Acc. Chem. Res, 46, 1125 (2013).

3. Y. V. Mikhaylik and J. R. Akridge, J. Electrochem. Soc., 151, A1969 (2004).

4. F. Y. Fan, W. C. Carter, and Y.-M. Chiang, Adv. Mater, 27, 5203 (2015).

5. Z. Liu, D. Hubble, P. B. Balbuena, and P. P. Mukherjee, Phys Chem Chem Phys, 17, 9032 (2015).

6. M. Cuisinier et al., J. Phys. Chem. Lett., 4, 3227 (2013).

7. K. H. Wujcik et al., Adv. Energy Mater, 5, 1500285 (2015).

8. M.-K. Song, E. J. Cairns, and Y. Zhang, Nanoscale, 5, 2186 (2013)

9. C. Barchasz et al., Anal. Chem., 84, 3973 (2012).

10. G. Yang, S. Shi, J. Yang, and Y. Ma, J Mater Chem A, 3, 8865 (2015).

11. S. Waluś et al., Adv. Energy Mater., 5, 1500165 (2015).

12. K. A. See et al., J. Am. Chem. Soc., 136, 16368 (2014).

13. P. Dubois, J. P. Lelieur, and G. Lepoutre, Inorg. Chem., 27, 73 (1988).

14. J.-M. Letoffe, J. Blanchard, and J. Bousquet, Bull. Soc. Chim. Fr., 395 (1976).

15. J. A. Gladysz, V. K. Wong, and B. S. Jick, Tetrahedron, 35, 2329 (1979).

16. R. A. Sharma, J. Electrochem. Soc., 119, 1439 (1972).

17. Z. Feng et al., J. Power Sources, 272, 518 (2014)

18. H. Park, H. S. Koh, and D. J. Siegel, J. Phys. Chem. C, 119, 4675 (2015).

19. J.-M. Letoffe, R. Joly, J. Thourey, G. Perachon, and J. Bousquet, J. Chim. Phys., 71, 427 (1974).

20. J.-M. Letoffe, J.-M. Blanchard, and J. Bousquet, Bull. Soc. Chim. Fr., 485 (1975).

21. J.-M. Letoffe, J. Thourey, G. Perachon, and J. Bousquet, Bull. Soc. Chim. Fr., 424 (1976).

22. K. Tatsumi et al., Angew. Chem. Int. Ed. Engl., 29, 422 (1990).

23. K. Tatsumi et al., Organometallics, 12, 352 (1993).

24. K. Tatsumi, H. Kawaguchi, K. Inoue, K. Tani, and R. E. Cramer, Inorg. Chem., 32, 4317 (1993).

25. A. Demortier, P. Chieux, and G. Lepoutre, Bull. Soc. Chim. Fr., 3421 (1971).

26. T. H. Elmer, I. D. Chapman, and M. E. Nordberg, J. Phys. Chem., 67, 2219 (1963).

27. D. Jackman and C. Keenan, J. Inorg. Nucl. Chem., 30, 2047 (1968)

28. D. Lee and C. Jensen, J. Chem. Educ., 77, 629 (2000).

29. C. Zu, M. Klein, and A. Manthiram, J. Phys. Chem. Lett., 5, 3986 (2014).

30. P. Swift, Surf. Interface Anal., 4, 47 (1982).

31. Z. Tian, M. W. C. Dharma-wardana, Z. H. Lu, R. Cao, and L. J. Lewis, Phys Rev B, 55, 5376 (1997).

32. D. Aurbach et al., J. Electrochem. Soc., 156, A694 (2009).

33. B. J. Lindberg et al., Phys. Scr., 1, 286 (1970).

34. U. Gelius, Phys. Scr, 9, 133 (1974).

35. R. Steudel and Y. Steudel, Chem. - Eur. J., 19, 3162 (2013).

36. C. F. Bohren and D. R. Huffman, in Absorption and Scattering of Light by Small Particles, p. 286, Wiley-VCH Verlag GmbH (2007).

37. J. Y. Koh et al., J. Electrochem. Soc., 161, A2133 (2014).

38. Y. Malozovsky, L. Franklin, C. Ekuma, and D. Bagayoko, Int. J. Mod. Phys. B, 29, 1542006 (2015)

39. Y. Yang et al., J. Am. Chem. Soc., 134, 15387 (2012). 